\title{
A Comparison of Metered-Dose Inhaled Albuterol Versus Endotracheal Liquid Bolus Albuterol for the Treatment of Bronchoconstriction
}

\author{
Donald A Johnston PhD RRT RN, \\ Tim W Gilmore MHS RRT-NPS-ACCS CPFT AE-C, \\ and Kevin P Gosselin PhD
}

\begin{abstract}
INTRODUCTION: Aerosolized albuterol delivery is a mainstay treatment for bronchoconstriction; however, almost no data exist that evaluate the clinical outcome of instillation of an endotracheal liquid bolus (ELB) of a bronchodilator directly into the airway. METHODS: This randomized trial sought to evaluate the efficacy of albuterol lavage via artificial airway with accompanied patient positioning. Subjects receiving mechanical ventilation for acute respiratory failure with clinical manifestations of bronchoconstriction were assigned to initially receive either traditional albuterol via metered-dose inhaler (MDI) or albuterol via ELB lavage with follow-up administration of the other therapy after a 4-h washout period. Clinical data were collected at baseline and at 5 and 30 min post-treatment. RESULTS: Fourteen subjects ( 5 males, 9 females; mean age of 57.5 y) were included in this study. In the group receiving initial ELB, peak airway pressure decreased significantly $(P=.02)$, and a significant decrease in airway resistance mean scores was seen from baseline to 30 min post-treatment $(P<.001)$ and from 5 to $30 \mathrm{~min}$ post-treatment $(P=.003)$, with no significant effects seen with follow-up MDI. In the initial MDI treatment group, no significant effect on peak airway pressure or airway resistance was noted. $\mathrm{S}_{\mathrm{pO}_{2}}$ increased at 5 min post-treatment with ELB. In contrast, $\mathrm{S}_{\mathrm{pO}_{2}}$ decreased 30 min post-treatment with MDI. Mean arterial pressure decreased post-treatment with ELB. The pattern in heart rate change post-treatment with ELB was similar to that post-treatment with MDI, with a significant increase at the 5-min interval from baseline $(P<.01)$, followed by a significant decrease at the 30 -min interval $(P<.001)$. There were no differences in dynamic compliance at each time interval following administration of both the MDI $(P=.92)$ and ELB conditions $(P=.18)$. CONCLUSIONS: ELB albuterol lavage may be a viable option to reverse bronchoconstriction in intubated patients with limited response to traditional aerosolized albuterol via MDI. Key words: albuterol liquid bolus; albuterol lavage; novel use albuterol. [Respir Care 2015;60(5):627-635. (c) 2015 Daedalus Enterprises]
\end{abstract}

\section{Introduction}

In the United States, according to the latest National Health Interview Survey (2006-2008), over $8 \%$ of the United States population has asthma. ${ }^{1,2}$ Of the almost 19

\footnotetext{
Dr Johnston was affiliated with the Louisiana State University Health Sciences Center, Shreveport, Louisiana, at the time of this study but is currently affiliated with University Health Shreveport, Shreveport, Louisiana. Mr Gilmore is affiliated with the Louisiana State University Health Sciences Center, Shreveport, Louisiana. Dr Gosselin is affiliated with Texas A\&M Health Science Center, Bryan, Texas.
}

million adults with asthma, ${ }^{2}$ a large portion will experience an exacerbation and require some form of emergent care. In 2001, The Epidemiology and Natural History of Asthma: Outcomes and Treatment Regimens (TENOR)

\footnotetext{
The authors have disclosed no conflicts of interest.
}

Correspondence: Donald A Johnston PhD RRT RN, University Health Shreveport, 1450 Claiborne Avenue, Shreveport, LA 71130. E-mail: DonaldAJohnston@gmail.com.

DOI: $10.4187 /$ respcare.03494 
study documented a high prevalence of asthma-related hospitalizations and emergency department visits in a multicenter prospective cohort of 4,756 subjects ranging from $6 \mathrm{y}$ of age to adult. All TENOR study subjects were considered difficult to treat, and approximately one in 10 reported a history of intubation for asthma. ${ }^{3}$

See the Related Editorial on page 756

It has been well-established that, despite multiple advances in asthma management and care, exacerbations continue as a cause of morbidity, imposing significant burden upon the health-care system. ${ }^{4}$ In 2005 , a large multi-center study by Griswold et al ${ }^{5}$ evaluated adults with acute asthma in 83 different United States emergency departments and identified older age, non-white race, and lower socioeconomic status as being associated with a higher number of emergency department visits, and those subjects were more likely to be intubated as a result of an asthma exacerbation. Recently, Strid et $\mathrm{al}^{6}$ published $16 \mathrm{y}$ worth of nationwide, population-based, cohort study data that evaluated firsttime status asthmaticus hospitalizations in Denmark for subjects of all ages. The group evaluated the clinical course of over 5,000 subjects and documented that $10.1 \%$ of firsttime status asthmaticus subjects were admitted to the ICU. Moreover, $3.2 \%$ of these subjects died within $30 \mathrm{~d}$ of admission for status asthmaticus. This mortality rate may not be representative of status asthmaticus mortality rates in the United States. However, Peters et $\mathrm{al}^{7}$ performed a retrospective observational study over a 30 -y period to evaluate status asthmaticus subjects admitted to their medical ICU, and $61 \%$ of 227 subjects required intubation due to asthma exacerbation, although mortality was $<1 \%$.

Although the status asthmaticus mortality rate is relatively low overall, a significant number of patients with severe asthmatic disease respond poorly to conventional treatments. In 2011, Rodrigo ${ }^{8}$ evaluated 100 studies, including systematic reviews, randomized trials, and observational studies, to determine the effectiveness and safety of common interventions for asthma exacerbations. In short, of the identified standard therapies, inhaled short-acting $\beta$ agonists are still considered the mainstay of treatment for acute asthma. However, more nontraditional therapies, such as inhaled or intravenous magnesium sulfate, inhaled helium-oxygen gas, and anesthetic gases, have gained credibility as viable options for those patients refractory to typical intervention. ${ }^{8,9}$

Endotracheal liquid bolus (ELB) administration of bronchodilator medication has not been empirically studied. We hypothesized that liquid bolus administration of a bronchodilator directly into an endotracheal tube (ETT) would be more effective in the treatment of acute bronchoconstriction than administration via metered-dose inhaler (MDI), as determined by peak airway pressure, plateau

\section{QUICK LOOK}

\section{Current knowledge}

The standard of care for the treatment of asthma includes inhaled short-acting $\beta$ agonists via metered-dose inhaler (MDI) or small-volume nebulizer. Other options for bronchodilator delivery have not been shown to be superior to the current standard.

\section{What this paper contributes to our knowledge}

In a small group of intubated, mechanically ventilated subjects with acute respiratory failure and evidence of bronchoconstriction, a liquid bolus of albuterol delivered to the trachea provided similar bronchodilation compared with MDI delivery. No safety issues were identified in this pilot study.

pressure, airway resistance $\left(\mathrm{R}_{\mathrm{aw}}\right), \mathrm{S}_{\mathrm{pO}_{2}}$, dynamic compliance, and mean arterial pressure.

Our hypothesis is based on the biophysics of fluid flow in constricted airways, ${ }^{10}$ as well as the existing body of knowledge on the deposition of liquid bolus surfactant. ${ }^{11-14}$ The purpose of this study was to compare the effectiveness of liquid bolus bronchodilators versus traditional methods, namely MDI, in the treatment of acute bronchoconstriction in mechanically ventilated subjects.

Gas-powered small-volume nebulizers were not used in this study because MDI delivery is the most widely used technique for bronchodilator delivery in intubated patients at our institution. With MDI administration, 3 basic styles of spacing adapter are available: (1) elbow, (2) in-line, and (3) chamber devices. ${ }^{15}$ The chamber-style device or the bidirectional minispacer was used in this study, as it was shown to deliver the most medication to an intubated, mechanically ventilated patient. ${ }^{15-17}$

\section{Methods}

\section{Design}

This study was a randomized trial using a 2-group pretest-posttest-posttest sequence. The study was approved by the institutional review board. Informed consent was obtained from each subject or an immediate family member before inclusion in the study. Each subject was randomized to receive one of 2 modalities of treatment, followed by the alternative treatment (standard care) after a 4-h washout period to reduce carryover effect. Each subject served as their own control. Dependent variables were peak airway pressure, $\mathrm{R}_{\mathrm{aw}}, \mathrm{S}_{\mathrm{pO}_{2}}$, heart rate, and dynamic compliance.

Patients with asthma and COPD who are on long-term $\beta_{2}$-agonist therapy, such as albuterol, may develop a toler- 
ance to sympathomimetics, resulting in less of a $\beta_{2}$-agonist response. ${ }^{18,19}$ Although this was a consideration, it was accounted for through randomization of subjects. Preservativefree albuterol was used in an attempt to prevent potential paradoxical bronchoconstriction caused by preservatives. ${ }^{20-22}$

\section{Inclusion Criteria}

Only adults ( $>18$ y of age) were considered eligible as subjects. Mechanically ventilated subjects with assumed bronchoconstriction were included if their clinical features included any of the following: high peak airway pressures ( $>30 \mathrm{~cm} \mathrm{H}_{2} \mathrm{O}$ ), auto-PEEP (PEEP in lungs above set PEEP), and/or hypercapnia $\left(\mathrm{P}_{\mathrm{aCO}}>45 \mathrm{~mm} \mathrm{Hg}\right)$. Subjects were excluded if any of the following clinical features were present: $<18$ or $>75 \mathrm{y}$ of age, inability to obtain informed consent, active myocardial ischemia, uncontrolled hypotension or hypertension, acute or uncompensated heart failure, increased intracranial pressure, spinal cord injury above T4, seizures refractory to anticonvulsant therapy, positive serum $\beta$ human chorionic gonadotropin indicating pregnancy, or treatment with any other experimental therapy within $30 \mathrm{~d}$ before screening.

\section{Instrumentation}

At the time of recruitment, all subjects were ventilated on a Servo 300 (Siemens-Elema, Solna, Sweden) with continuous positive-pressure ventilation in pressure-regulated volume control, volume support, and synchronized intermittent mandatory ventilation. All subjects were intubated with a SIMS Portex Blue Line cuffed ETT (Keene, New Hampshire). During the instillation of medication via ELB, the subject was ventilated via a self-inflating bagvalve device at an $\mathrm{F}_{\mathrm{IO}_{2}}$ of 1.0. In the MDI group, a cylindrical collapsible spacer chamber (AeroVent, Monaghan Medical, Plattsburgh, New York) or a bidirectional minispacer (Airlife dual spray minispacer, Allegiance Healthcare, McGaw Park, Illinois) was placed in line on the inspiratory limb of the ventilator circuit $15 \mathrm{~cm}$ from the Y-piece to deliver the medication from the MDI to the subject. Aerosol drug delivery with an MDI chamber device was reported to be equivalent to the bidirectional in-line spacer device. ${ }^{17} \mathrm{~S}_{\mathrm{pO}_{2}}$ was recorded with a Nellcor N-595 pulse oximeter (Nellcor/Covidien, Boulder, Colorado).

\section{Procedures}

Upon admission to the study, each subject was randomized into one of 2 groups. Six subjects were randomly assigned to receive the control treatment first (MDI albuterol), followed by the experimental treatment (ELB albuterol) after a 4-h washout period. Eight subjects were randomly assigned to receive the experimental treatment first, followed by the control treatment after a 4-h washout period.
Before treatment, the mechanical ventilator was set to deliver a specific tidal volume $\left(\mathrm{V}_{\mathrm{T}}\right)$ with a square-wave flow-time profile. Mandatory breathing frequency and $V_{T}$ were adjusted in each subject by the attending physician. Cardiopulmonary variables and mechanical ventilator parameters were documented $5 \mathrm{~min}$ before each treatment, specifically noting peak airway pressure, plateau pressure, mean arterial pressure, $\mathrm{F}_{\mathrm{IO}_{2}}$, breathing frequency, PEEP, auto-PEEP, inspiratory time, $\mathrm{V}_{\mathrm{T}}$, minute ventilation, inspiratory flow, heart rate, and $\mathrm{S}_{\mathrm{pO}_{2}}$.

Subjects in the ELB group were positioned on their left sides, removed from mechanical ventilation, and immediately administered one-half unit dose of albuterol $(1.25 \mathrm{mg})$ mixed with $3 \mathrm{cc}$ of $\mathrm{NaCl}$ in bolus form via the ETT. With the subject on his left side, a self-inflating bag-valve device was attached to the oral ETT, and the subject was ventilated for $1 \mathrm{~min}$ at a rate consistent with the prior set ventilatory rate. The subject was then positioned on his right side, and the above procedure was repeated, beginning with a second instillation of albuterol, followed by 1 min of manual bag ventilation. Finally, the subject was positioned supine and returned to mechanical ventilation at the previous settings. Cardiopulmonary variables and mechanical ventilator parameters were assessed and recorded at 5- and 30-min intervals post-treatment intervention.

Subjects in the MDI group received standard aerosol therapy. A spacer was placed $15 \mathrm{~cm}$ from the Y-piece on the inspiratory side of the ventilator circuit, and an MDI canister of albuterol (90 $\mu \mathrm{g} / \mathrm{puff}$; Schering, Kenilworth, New Jersey) was connected to the spacer. The canister was shaken before each actuation. Each actuation was administered at onset of gas flow at 30-s intervals for a total of 4 puffs $(360 \mu \mathrm{g})$ of albuterol. Cardiopulmonary variables and mechanical ventilator parameters were assessed and recorded at 5- and 30-min intervals post-treatment.

\section{Statistical Analysis}

The following parameters were calculated: $\mathrm{R}_{\mathrm{aw}}=$ (peak airway pressure - plateau pressure)/inspiratory flow and dynamic compliance $=\mathrm{V}_{\mathrm{T}}$ / (peak airway pressure - total PEEP). The analysis of breaths obtained with end-inspiratory and end-expiratory occlusions was described in detail by Dhand et al. ${ }^{23}$ Correction for gas compression in the tubing was included in the calculation of dynamic compliance. The resistance of the ETT was not subtracted in determining the $\mathrm{R}_{\mathrm{aw}}$ because the resistance of the ETT is consistent and not likely to be an important factor in influencing the change in $\mathrm{R}_{\mathrm{aw}}$ after treatment with albuterol.

An a priori power analysis for a $2 \times 3$ repeated-measures analysis of variance with an $\alpha$ error probability of .05 , power of 0.8 , expected correlation among repeated measures of 0.75 , and non-sphericity correction of $\varepsilon=0.66$ required a sample of 14 subjects. Following Senn's rec- 
Table 1. Characteristics Among Groups

\begin{tabular}{lcc}
\hline \hline \multicolumn{1}{c}{ Characteristic } & $\begin{array}{c}\text { MDI and Liquid } \\
(n=6)\end{array}$ & $\begin{array}{c}\text { Liquid and MDI } \\
(n=8)\end{array}$ \\
\hline Age (mean $\pm \mathrm{SD}), \mathrm{y}$ & $58 \pm 11.2$ & $57.1 \pm 8.1$ \\
Males, $n$ & 3 & 2 \\
Females, $n$ & 3 & 6 \\
MDI $=$ metered-dose inhaler & & \\
\hline
\end{tabular}

ommendations ${ }^{24}$ for evaluation of crossover designs, difference scores were calculated across each treatment condition at each time interval (5-min and 30-min after drug administration). Data were then assessed to determine their suitability for parametric statistical analysis. The peak airway pressure data were not normally distributed, and dynamic compliance and $\mathrm{R}_{\mathrm{aw}}$ variables violated the homogeneity of variance assumption. A reversed-scored reciprocal transformation $\left(1 /\left[\mathrm{X}_{\text {highest }}-\mathrm{X}_{\mathrm{i}}\right]\right)$ was then applied. Following the transformation, the distribution and homogeneity of variance violations were corrected, allowing for parametric statistical testing.

\section{Results}

\section{Subjects}

Fourteen subjects (5 males, 9 females; $42-74$ y old) receiving mechanical ventilation for acute respiratory failure due to asthma or COPD exacerbation were enrolled in the study as shown in Table 1.

\section{Characteristics at Baseline}

A comparison of mean baselines by paired $t$ tests showed a statistically significant difference in peak airway pressure, $\mathrm{R}_{\mathrm{aw}}$, and dynamic compliance between the 2 groups, which is accounted for by the randomized crossover of subjects. Specifically, those subjects who received the ELB treatment before MDI (liquid/MDI group) showed significant changes from baseline in $\mathrm{R}_{\mathrm{aw}}$ and dynamic compliance compared with the second baseline values recorded before MDI administration. This indicates that the residual effects of ELB treatment persisted beyond the 4-h washout period. Otherwise, subjects did not differ significantly at baseline in the dependent variables. Accordingly, baseline scores were used as a covariate in the analysis of peak airway pressure, $\mathrm{R}_{\mathrm{aw}}$, and dynamic compliance to account for mean group differences in these variables.

\section{Treatment Effects}

The effects of albuterol administered via MDI and ELB on cardiopulmonary mechanics are shown in Table 2.

\section{Peak Airway Pressure}

No changes were observed in mean peak airway pressure difference scores following MDI administration $(P=.36)$. For the ELB condition, the Mauchly test indicated that the assumption of sphericity had been violated $(P<.01)$. Accordingly, multivariate tests are reported $(\varepsilon=.59)$. Following ELB treatment, peak airway pressure decreased significantly compared with baseline $(P=.02)$. Post hoc tests using the Bonferroni correction revealed no significant difference from baseline to $5 \mathrm{~min}$ post-treatment $(P=.76)$ and from $5 \mathrm{~min}$ post-treatment to $30 \mathrm{~min}$ post-treatment $(P=.10)$, but showed significant decreases at $30 \mathrm{~min}$ post-treatment $(P=.004)$.

$\mathbf{R}_{\text {aw }}$

No changes were seen in mean $\mathrm{R}_{\mathrm{aw}}$ scores following MDI treatment. For the ELB condition, the Mauchly test indicated that the assumption of sphericity had been violated $(P<.01)$, meriting reporting of multivariate tests $(\varepsilon=.63)$. Following ELB treatment, $\mathrm{R}_{\mathrm{aw}}$ scores were significantly different $(P<.001)$. Pairwise comparisons revealed no significant differences from baseline to $5 \mathrm{~min}$ post-treatment $(P=.63)$. A significant decrease in mean $\mathrm{R}_{\mathrm{aw}}$ scores was seen from baseline to $30 \mathrm{~min}$ post-treatment $(P<.001)$ and from 5 min post-treatment to $30 \mathrm{~min}$ post-treatment $(P=.003)$.

\section{Heart Rate}

For the MDI condition, the Mauchly test indicated that the assumption of sphericity had been violated for heart rate $(P<.05)$, resulting in multivariate test reporting $(\varepsilon=.69)$. For the MDI condition, heart rate was significantly affected following drug administration $(P=.004)$. Heart rate was significantly higher at 5 min post-treatment compared with both baseline $(P=.009)$ and $30 \mathrm{~min}$ posttreatment $(P=.001)$. No differences were seen in heart rate from baseline to the 30 -min interval $(P=.23)$, demonstrating a rapid increase following drug administration with a return to normal levels at the 30-min interval. Heart rate was also significantly different at the 2 time intervals following ELB treatment $(P<.001)$. The pattern in heart rate change in the ELB condition was similar to that in the MDI condition with a significant increase at the 5-min interval from baseline $(P<.01)$, followed by a significant decrease at the 30 -min interval $(P<.001)$. Baseline and 30-min heart rate scores did not differ significantly $(P=.53)$. 
MDI vs Liquid Bolus Albuterol

Table 2. Cardiopulmonary Mechanics

\begin{tabular}{|c|c|c|c|c|c|c|}
\hline \multirow{2}{*}{ Variable } & \multicolumn{3}{|c|}{ MDI } & \multicolumn{3}{|c|}{ Liquid } \\
\hline & Baseline & $5 \mathrm{~min}$ & $30 \mathrm{~min}$ & Baseline & $5 \mathrm{~min}$ & $30 \mathrm{~min}$ \\
\hline Peak airway pressure, $\mathrm{cm} \mathrm{H}_{2} \mathrm{O}$ & $28.9 \pm 5.6$ & $28.5 \pm 5.2$ & $28.4 \pm 5.6$ & $33.4 \pm 8.5$ & $31.6 \pm 6.9$ & $29.5 \pm 6.6$ \\
\hline $\mathrm{R}_{\mathrm{aw}}, \mathrm{cm} \mathrm{H}_{2} \mathrm{O} / \mathrm{L} / \mathrm{s}$ & $10.9 \pm 3.3$ & $10.6 \pm 2.5$ & $11.1 \pm 3.6$ & $16.0 \pm 4.8$ & $12.2 \pm 3.6$ & $9.1 \pm 3.7$ \\
\hline Dynamic compliance, $\mathrm{mL} / \mathrm{cm} \mathrm{H}_{2} \mathrm{O}$ & $29.1 \pm 8.2$ & $29.3 \pm 8.2$ & $29 \pm 9.2$ & $23.9 \pm 8.3$ & $26.2 \pm 9.9$ & $26.9 \pm 8.3$ \\
\hline Heart rate, beats/min & $98.1 \pm 15.8$ & $100.7 \pm 14.8$ & $99.4 \pm 15.7$ & $98.6 \pm 15.8$ & $109.4 \pm 12.9$ & $110.6 \pm 14.6$ \\
\hline $\mathrm{S}_{\mathrm{pO}_{2}}$ & $97.1 \pm 3.0$ & $96.9 \pm 2.5$ & $95.8 \pm 2.8$ & $96.8 \pm 2.5$ & $97.9 \pm 2.8$ & $96.5 \pm 2.6$ \\
\hline Mean arterial pressure & $85.1 \pm 12.3$ & $84.3 \pm 11.0$ & $82.4 \pm 9.6$ & $86.1 \pm 8.3$ & $78.3 \pm 9.0$ & $79.1 \pm 9.5$ \\
\hline $\begin{array}{l}\mathrm{MDI}=\text { metered-dose inhaler } \\
\mathrm{R}_{\mathrm{aw}}=\text { airway resistance }\end{array}$ & & & & & & \\
\hline
\end{tabular}

\section{Dynamic Compliance}

There were no differences in dynamic compliance at each time interval following administration for both the MDI $(P=.92)$ and ELB $(P=.18)$ conditions.

\section{Discussion}

\section{Current Evidence-Based Asthma Management and Care}

In 2007, the Expert Panel Report 3 (EPR-3) Guidelines for the Diagnosis and Management of Asthma were released with updated recommendations for managing asthma long-term and exacerbations. Asthma is considered a complex inflammatory disease ${ }^{25}$ often difficult to treat during the exacerbation phase. As the pathophysiology of bronchoconstriction is not well understood but remains a dominant event during exacerbations, airway narrowing must be reversed as soon as possible. Of the 4 components of asthma management (assessment and monitoring, education, environmental control, and pharmacologic therapy), timely medication administration is most vital to the success of patient management during exacerbations. By reversing bronchospasms, administration of pharmacologic therapy may result in reduction of exacerbation severity. It is essential, however, during exacerbations that quick-relief medications are administered rapidly and effectively. According to EPR-3, short-acting $\beta$ agonists are the mainstay treatment for acute symptoms and exacerbations, as they are considered the most effective medication in relieving acute bronchospasms with few negative cardiovascular side effects. ${ }^{26}$

Refractory asthma, also known as fatal asthma, near fatal asthma, severe asthma, steroid-dependent and/or steroid-resistant asthma, brittle asthma, or irreversible asthma as defined by the American Thoracic Society, encompasses a variety of criteria for which there is no consensus among other groups.${ }^{27}$ It is agreed, however, that refractory asthma describes an asthmatic condition that does not respond to traditional intervention and therapies and that this presents a challenge during an exacerbation. Current evidence-based practice guidelines are explicit for standard asthma management in both out-patient and in-patient settings, but there remain an evidence deficit and overall lack of agreement as to the best means of optimal pharmacotherapy in the refractory asthma patient population. Both inhaled and systemic corticosteroids have long been the mainstay of treatment for patients with severe asthma; nevertheless, a large number of patients continue refractory to standard care. Evidence is lacking for the use of so-called steroidsparing agents, such as azathioprine, chloroquine, cyclosporine, gold, and methotrexate. ${ }^{28-32}$ However, add-on therapies, such as macrolides, anti-immunoglobulin E, tumor necrosis factor alpha inhibitors, cytokine receptor antagonists, and bronchial thermoplasty, are developing as alternative options in refractory asthma care. ${ }^{33,34}$

\section{Inhaled Versus Systemic Route of Short-Acting $\boldsymbol{\beta}$-Agonist Administration}

According to the latest global strategy for asthma management and prevention report of the Global Initiative for Asthma, asthma treatment for adults is divided into controller and reliever categories, each administered via inhalation, orally, or parenterally (subcutaneous, intramuscular, or intravenous injection). Because inhaled medication is delivered directly to the site of the desired effect, and systemic side effect risk is relatively low, ${ }^{35-37}$ this route is preferred. Unfortunately, although many choices are available for inhalation delivery, not all devices are equally as effective. ${ }^{38}$

Albuterol is FDA-cleared for administration via the inhalation, oral, or parenteral route. ${ }^{37} \mathrm{~A}$ recent systematic review evaluated the additional use of intravenous albuterol as an adjunct to traditional inhaled therapy. Of the 109 studies appraised by Travers et al, ${ }^{39}$ only 3 met inclusion criteria, 2 of which were pediatric studies. Only lim- 
ited evidence supports the use of intravenous $\beta$ agonists in children, with no currently documented significant benefit in adults.

\section{Endotracheal Bolus}

Few studies have been published evaluating the endotracheal administration of a short-acting $\beta$ agonist to an asthma patient refractory to inhaled or intravenous shortacting $\beta$ agonists. In 2004, Carroll and Goodman ${ }^{40}$ reported 2 cases of direct albuterol instillation via an ETT in infants. Patient 1 was a 7-week-old infant presenting to the emergency department with respiratory distress refractory to consecutive and alternating treatments of albuterol and racemic epinephrine. The patient continued with severe hypercarbia $\left(\mathrm{P}_{\mathrm{aCO}_{2}}\right.$ of $\left.130 \mathrm{~mm} \mathrm{Hg}\right)$ after intubation and an unsuccessful attempt to mechanically ventilate. The patient was given two 5-mg doses of undiluted albuterol via ETT lavage. Patient 2 was a 4-month-old infant presenting to the emergency department with a history of reactive airway disease and bronchopulmonary dysplasia refractory to continuous inhaled albuterol with intermittent ipratropium, subcutaneous epinephrine, sedation, and muscle relaxation. The patient continued with refractory hypoxemia $\left(\mathrm{S}_{\mathrm{pO}_{2}}\right.$ of $40-60 \%$ at $\mathrm{F}_{\mathrm{IO}_{2}}$ of 1.0$)$ after intubation and an unsuccessful attempt to mechanically ventilate. The patient was given two 5-mg doses of undiluted albuterol via ETT lavage. Both subjects had an almost immediate positive response, with increased aeration and arterial blood gas improvement.

\section{Methods of Bronchodilator Administration During Mechanical Ventilation}

Bronchodilators are administered to patients with bronchoconstriction during mechanical ventilation most commonly via MDI or small-volume nebulizer. In MDI administration, a bronchodilating medication is delivered to the patient via a pressurized canister and spacer device. The canister contains medication in the form of a micronized powder, suspended with a mixture of hydrofluoroalkanes and a dispersal agent. Small-volume nebulizers are used to deliver medication to the airway by changing the liquid medication into a fine mist or aerosol using a jet of air or oxygen that forces the liquid into a baffle, creating aerosol particles. ${ }^{41}$ In consideration of both methods, however, the delivery of medicated aerosol to the lower airway is affected by a number of variables, including location of the MDI or small-volume nebulizer with regard to the patient, mass median aerodynamic diameter, gas flow source, inspiratory flow pattern, inspiratory flow time, specific appliance type, physical and chemical properties of medication, airway anatomy, presence of airway secretions, and humidity of the inner circuit environment. ${ }^{15,42-44}$

\section{History of ELB}

Aside from the traditional approach to delivering aerosol therapy, there is an option to administer liquid medications via direct instillation into the ETT. The ETT route of administration is commonly used to deliver cardiac drugs during implementation of advanced cardiac life support protocols ${ }^{44,45}$ and is the preferred route of surfactant administration in premature neonates. ${ }^{46,47}$ In ELB instillation, medication is injected directly into the ETT of a mechanically ventilated patient and bagged using a selfinflating bag-valve device.

ELB treatment has long been an alternative method of administration of cardiac drugs, such as epinephrine, atropine, lidocaine, and naloxone, in emergencies when vascular access is unobtainable. ${ }^{45,46}$ The technique is also commonly used for surfactant administration in the management of respiratory distress syndrome in newborn infants. ${ }^{47,48}$ Animal studies showed ELB administration of surfactant to be significantly more effective in comparison with other forms of surfactant administration. ${ }^{11}$ In particular, this method was shown to deposit the administered medication evenly to all available pulmonary lobes when a patient is properly positioned and rotated accordingly. ${ }^{12}$

\section{Physics of ELB}

The principle behind the technique of ELB, as it is used in surfactant therapy, is the use of gravity to distribute the medication to all areas of the lung. In theory, the improved distribution of medications administered via ELB installation makes it an ideal method of administering bronchodilating medications versus traditional methods in which gas flow (ventilation) is the primary determinant of which areas receive medication. ${ }^{13,14,49}$ During aerosolized administration of bronchodilators, gases naturally follow the path of least resistance, ${ }^{10}$ and certain areas of the bronchial tree may receive up to 25 times more medication than other areas. ${ }^{50}$ With the complex airway variations found in lung disease, model simulations of airways, as reported by Byron et al, ${ }^{51}$ confirm that aerosol particle deposition is non-uniform and dependent on age, airway geometry, breathing patterns, postural position, particle characteristics, and device interaction.

$\beta_{2}$ agonists have long been recognized for their effectiveness in reducing and reversing bronchoconstriction. However, the challenge in the effective use of these drugs has been finding a means to deliver them to the areas in need of dilation. Several mechanical devices have been introduced for this purpose, such as the MDI with various spacers and adapters, small-volume and large-volume pneumatic nebulizers, ultrasonic nebulizers, powder inhalers, and endotracheal catheters. Additionally, numerous techniques have evolved in an attempt to increase the efficacy of these devices, including humidity manipulation, 
high/low-flow ventilatory modes, heliox (helium-oxygen mixture) administration, and intravenous $\beta_{2}$ agonist delivery. ${ }^{52,53}$ None of these devices or techniques has proven consistently effective in reversing bronchoconstriction, and consequently, there is no one universally accepted method of treatment for acute refractory bronchoconstriction. Meanwhile, ELB has become a widely accepted method for the delivery of drugs, such as surfactant, epinephrine, atropine, lidocaine, and naloxone. Because ELB uses gravity rather than ventilation to deliver medication, it is able to reach most areas of the lungs, ${ }^{12}$ including those areas difficult to ventilate as a result of bronchoconstriction.

The data given above suggest that administration of albuterol via ELB, with side-to-side positioning, is more effective compared with MDI in rapidly reducing bronchoconstriction. Four key variables indicative of bronchoconstriction were evaluated: peak airway pressure, $\mathrm{R}_{\mathrm{aw}}$, heart rate, and dynamic compliance. Peak airway pressure and $\mathrm{R}_{\mathrm{aw}}$ were found to be significantly improved in the ELB phase of the study, with no significant improvement in the MDI phase.

We hypothesized that subjects who were randomized to receive ELB before MDI (liquid/MDI group) would have a greater response with the MDI treatment due to the bronchodilation achieved with the ELB technique. However, this effect was not appreciated. The order of treatment did not influence the effectiveness of either treatment in consideration of the variables measured. This indicates that subjects received no greater benefits from MDI when it followed ELB treatment.

Those subjects who received the ELB treatment before MDI showed lasting effects in $\mathrm{R}_{\mathrm{aw}}$ and dynamic compliance at the baseline MDI reading ( $4 \mathrm{~h}$ after ELB), indicating residual effects beyond the washout period. This demonstrates that subjects remain bronchodilated for an extended period of time following treatment via ELB, in contrast to the standard 4-h period of efficacy for both MDI and nebulized albuterol. ${ }^{54}$ Because a successful extubation from mechanical ventilation requires reversal of bronchoconstriction, the return to pre-treatment respiratory mechanics may indicate that treatment is ultimately ineffective. Conversely, a treatment that results in lasting effects beyond the duration of action of the medication may indicate a reversal of the condition and allow for prompt extubation. Future studies should include an additional data check at $4-6 \mathrm{~h}$ following treatment to determine whether and when bronchoconstriction may reoccur.

Interestingly, during the MDI phase of the study, the only significant effect was increased heart rate. Due to limited resources and non-funding of this study, only traditional vital signs were obtained throughout, including heart rate, breathing frequency, mean arterial pressure, and $\mathrm{S}_{\mathrm{pO}_{2}}$. Any technique or device that relies on ventilation for the delivery of medication is inevitably only effective within those areas that allow ventilation. Bronchoconstricted airways are intrinsically resistant to ventilation. To ventilate these areas, one must increase the driving pressure to overcome this resistance to ventilation, often resulting in trauma and increasing morbidity and mortality. ${ }^{10}$ ELB presents a less traumatic yet effective solution to this problem.

ELB of $\beta_{2}$ agonists is not entirely without complications. All subjects coughed during ELB administration. Although the $\mathrm{S}_{\mathrm{pO}_{2}}$ increased following ELB treatment, the heart rate also increased. As shown in Table 2, however, the mean change in heart rate following ELB was 12 beats/min. Although this increase is statistically significant, it is not typically seen as clinically noteworthy or troublesome in the average patient. It is also important to note that the quantity of albuterol used in the MDI treatment was $360 \mu \mathrm{g}$ versus $2.5 \mathrm{mg}$ administered via ELB, a 7-fold difference, which resulted in a relatively negligible heart rate change. Interestingly, the 12-point heart rate change seen following ELB treatment is $\sim 4.6$ times the heart rate increase seen following MDI treatment, despite the 7-fold increase in medication administered. Prior to treatment with albuterol, subjects were sedated with midazolam, lorazepam, propofol, or a combination thereof. As subjects were heavily sedated, none were observed spontaneously breathing at the time of the pulmonary mechanics acquisition; however, some spontaneous efforts were noted during ELB.

At our institution, our standard of care in the adult population dictates that, when $2.5 \mathrm{mg}$ of albuterol is ordered, the respiratory therapist chooses whether an MDI or smallvolume nebulizer is used. This policy is based on the premise that 4 puffs of MDI albuterol are as efficacious as $2.5 \mathrm{mg}$ of nebulized albuterol. ${ }^{55}$

The idea for this study came to fruition over a 5-y period of receiving children in the pediatric emergency room. Paramedics or emergency medical technicians would bring a child found unable to breathe due to status asthmaticus into the pediatric emergency room handing over the Ambu bag and an empty MDI canister of albuterol. All too often, my report was generally "I gave them the whole MDI canister and I still can't move any air." Prior to arrival at our onsite facility, many of the children could not be oxygenated or ventilated in the field. Unfortunately, even some patients with initial reversal of their hypoxemia and hypercarbia suffered anoxic brain injury and remained in the pediatric ICU for many weeks. A portion of these children required a tracheostomy and were placed on home ventilation at discharge.

How can a bronchodilator be delivered via an ETT to a bronchoconstricted area without air flow? Studies using surfactant showed promise with gravity and positioning. As registered respiratory therapists, we routinely instill surfactant in neonates in the neonatal ICU. Could this same principle be used in children with asthma? This study is the first step in a process to attempt this procedure on pediatric patients. 


\section{Limitations}

This study was limited in seeking to establish the overall efficacy of the proposed treatment and did not assess the duration of the bronchodilation effect, proper dosing schedule, or compatibility with other disease processes. We were restricted in our access to adjunct diagnostic and lab values because of limited resources and non-funding of the study. In the future, it may be helpful to evaluate serum potassium levels in correlation with albuterol therapy administration. Additionally, baseline airway resistance was much lower in the MDI group. This could be a contributor to the negligible change seen in this particular group, owing to the statistically insignificant decrease in post-intervention (MDI) airway resistance. Moreover, the sample size is small, and the data are generated from a single site. These results should be replicated before widespread adoption of this technique.

This study included subjects with asthma and/or COPD. Further studies should be limited to one of these disease processes. Asthma patients may respond favorably to one 2.5-mg dose of albuterol via ELB, whereas subjects with COPD may require higher doses of medication or repeated doses due to albuterol tolerance. Albuterol toxicity was not assessed, and potassium was not monitored in this study. Baseline and post-treatment arterial blood gases were not obtained to assess ventilatory status, but should be in future studies.

\section{Conclusions}

In summary, instillation of ELB albuterol coupled with subject positioning as described in the procedures section above may be useful in the emergency treatment of intubated subjects for the sole purpose of treating bronchoconstriction that remains refractory to standard therapies. We do not advocate this method as front-line therapy; we solely wish to present this as another option after other treatment modalities have failed. However, it is unclear if this therapeutic intervention would be useful in the ongoing treatment of status asthmaticus. If the next level of intervention is in favor of extracorporeal membrane oxygenation, there may be little risk in attempting ELB albuterol. The ultimate treatment modality choice is at the discretion of the attending physician.

ELB albuterol may play a role in the prehospital treatment of acutely bronchoconstricted patients with respiratory arrest by emergency medical personnel. Currently, for these patients, the emergency medical technician/ paramedic must intubate and manually bag using a bronchodilator via MDI or nebulizer. If the $\mathrm{R}_{\mathrm{aw}}$ or bronchoconstriction is so severe that manual bag ventilation is not successful, there may remain no other option for bronchodilator administration. The administration of ELB albu- terol can be performed quickly and with relative ease in the field to improve ventilation and oxygenation.

\section{REFERENCES}

1. Moorman JE, Zahran H, Truman B, Molla M. (2011) Current Asthma Prevalence-United States, 2006-2008. Atlanta: Epidemiology and Analysis Program office.

2. Schiller JS, Lucas JW, and Peregoy JA. (2012) Summary health statistics for US adults: National Health Interview Survey, 2011. National Center for Health Statistics. Vital Health Stat 10(256).

3. Chipps, BE, Zeiger RS, Borish L, Wenzel SE, Yegin A, Hayden ML, et al. Key findings and clinical implications from The Epidemiology and Natural History of Asthma: Outcomes and Treatment Regimens (TENOR) study. J Allergy Clin Immunol 2012;130(2):332e10342.e10.

4. Jackson DJ, Sykes A, Mallia P, Johnston SL. Asthma exacerbations: Origin, effect, and prevention. J Allergy Clin Immunol 2011;128(6): 1165-1174.

5. Griswold SK, Nordstrom CR, Clark S, Gaeta TJ, Price ML, Camargo CA Jr. Asthma exacerbations in North American adults: who are the "frequent fliers" in the emergency department? Chest 2005;127(5): 1579-1586.

6. Strid JM, Gammelager H, Johansen MB, Tønnesen E, Christiansen CF. Hospitalization rate and 30-day mortality among patients with status asthmaticus in Denmark: a 16-year nationwide populationbased cohort study. Clin Epidemiol 2013;5:345-355.

7. Peters JI, Stupka JE, Singh H, Rossrucker J, Angel LF, Melo J, Levine SM. Status asthmaticus in the medical intensive care unit: a 30-year experience. Respir Med 2012;106(3):344-348.

8. Rodrigo, G. Asthma in adults (acute). Clin Evid 2011;2011:1513.

9. Restrepo RD, and Peters J. Near-fatal asthma: recognition and management. Curr Opin Pulm Med 2008;14(1):13-23.

10. O'Grady K, Doyle DJ, Irish J, Gullane P. Biophysics of airflow within the airway: a review. J Otolaryngol 1997;26(2):123-128.

11. Tashiro K, Yamada K, Li WZ, Matsumoto Y, Kobayashi T. Aerosolized and instilled surfactant therapies for acute lung injury caused by intratracheal endotoxin in rats. Crit Care Med 1996;24(3):488-494.

12. Ueda T, Ikegami M, Rider ED, Jobe AH. Distribution of surfactant and ventilation in surfactant-treated preterm lambs. J Appl Physiol 1994;76(1):45-55.

13. Halpern D, Fujioka H, Takayama S, Grotberg JB. Liquid and surfactant delivery into pulmonary airways. Respir Physiol Neurobiol 2008; 163(1-3):222-231.

14. Waters SL, and Rothberg, JB. The propagation of a surfactant laden liquid plug in a capillary tube. Physics Fluids 2002;14(2):471-480.

15. Dhand R. Basic techniques for aerosol delivery during mechanical ventilation. Respir Care 2004;49(6):611-622.

16. Ebert J, Adams AB, and Green-Eide B. An evaluation of MDI (metered dose inhaler) spacers and adapters: their effect on the respirable volume of medication. Respir Care 1992;37(8):862-868.

17. Rau JL, Dunlevy CL, and Hill RL. A comparison of inline MDI actuators for delivery of a beta agonist and a corticosteroid with a mechanically ventilated lung model. Respir Care 1998;43(9):705-712.

18. Cottrel GP and Surkin HB. Pharmacology for respiratory care practitioners. Philadelphia: FA Davis; 1995.

19. Cooper PR, and Panettieri RA Jr. Steroids completely reverse albuterol-induced beta $_{2}$-adrenergic receptor tolerance in human small airways. J Allergy Clin Immunol 2008;122(4):734-740.

20. Beasley R, Fishwick D, Miles JF, Hendeles L. Preservatives in nebulizer solutions: risks without benefit. Pharmacotherapy 1998;18(1): 130-139.

21. Bateman E, Singh D, Smith D, Disse B, Towse L, Massey D, et al. Efficacy and safety of tiotropium Respimat SMI in COPD in two 
1-year randomized studies. Int J Chron Obstruct Pulmon Dis 2010; 5:197-208.

22. Alothman GA, Alsaadi MM, Ho BL, Ho SL, Dupuis A, Corey M, Coates AL. Evaluation of bronchial constriction in children with cystic fibrosis after inhaling two different preparations of tobramycin. Chest 2002;122(3):930-934.

23. Dhand R, Jubran A, and Tobin MJ. Bronchodilator delivery by metered-dose inhaler in ventilator-supported patients. Am J Respir Crit Care Med 1995;151(6):1827-1833.

24. Senn S. Testing for baseline balance in clinical trials. Stat Med 1994;13(17):1715-1726.

25. Barnes PJ. Severe asthma: advances in current management and future therapy. J Allergy Clin Immunol 2012;129(1):48-59.

26. National Asthma Education and Prevention Program. Expert Panel Report 3 (EPR-3): Guidelines for the Diagnosis and Management of Asthma-Summary Report 2007. J Allergy Clin Immunol 2007;120(5 Suppl):S94-S138.

27. American Thoracic Society. Proceedings of the ATS workshop on refractory asthma: current understanding, recommendations, and unanswered questions. Am J Respir Crit Care Med 2000;162(6):23412351.

28. Evans DJ, Cullinan P, and Geddes DM. Cyclosporin as an oral corticosteroid sparing agent in stable asthma. Cochrane Database Syst Rev 2001(2):CD002993.

29. Dean T, Dewey A, Bara A, Lasserson TJ, Walters EH. Azathioprine as an oral corticosteroid sparing agent for asthma. Cochrane Database Syst Rev 2004(1):CD003270.

30. Evans DJ, Cullinan P, and Geddes DM. Gold as an oral corticosteroid sparing agent in stable asthma. Cochrane Database Syst Rev 2001(2):CD002985

31. Davies H, Olson L, and Gibson P. Methotrexate as a steroid sparing agent for asthma in adults. Cochrane Database Syst Rev 2000(2): CD000391.

32. Dean T, Dewey A, Bara A, Lasserson TJ, Walters EH. Chloroquine as a steroid sparing agent for asthma. Cochrane Database Syst Rev 2003(4):CD003275.

33. Bhowmick B, and Singh D. Novel anti-inflammatory treatments for asthma. Expert Rev Respir Med 2008;2(5):617-629.

34. Torrego A, Solà I, Munoz AM, Roqué i Figuls M, Yepes-Nuñez JJ, Alonso-Coello P, Plaza V. Bronchial thermoplasty for moderate or severe persistent asthma in adults. Cochrane Database Syst Rev 2014; (3)CD009910.

35. Global Initiative for Asthma (GINA). Global strategy for asthma management and prevention, 2011. http://www.ginasthma.org/. Accessed November 26, 2014.

36. Elers J, Pedersen L, Henninge J, Lund TK, Hemmersbach P, Dalhoff $\mathrm{K}$, Backer V. Blood and urinary concentrations of salbutamol in asthmatic subjects. Med Sci Sports Exerc 2010;42(2):244-249.

37. Nephron Pharmaceuticals. Albuterol sulfate inhalation solution; 2007. http://www.nephronpharm.com/images/upload_images/file/ Albuterol\%200_5\%25.pdf. Accessed November 26, 2014.

38. Dolovich MB, Ahrens RC, Hess DR, Anderson P, Dhand R, Rau JL, et al. Device selection and outcomes of aerosol therapy: evidence-based guidelines: American College of Chest Physicians/American College of Asthma, Allergy, and Immunology. Chest 2005;127(1):335-371.

39. Travers AH, Milan SJ, Jones AP, Camargo CA Jr, Rowe BH. Addition of intravenous beta ${ }_{2}$-agonists to inhaled beta ${ }_{2}$-agonists for acute asthma. Cochrane Database Syst Rev 2012;(12):CD010179.

40. Carroll CL, and Goodman DM. Endotracheal albuterol treatment of acute bronchospasm. Am J Emerg Med 2004;22(6):506-507.

41. Hess DR. Aerosol delivery devices in the treatment of asthma. Respir Care 2008;53(6):699-723; discussion 723-725.

42. Kacmarek RM, Stoller JK, and Heuer, AJ. Egan's fundamentals of respiratory care, 10th edition. St Louis: Elsevier Mosby; 2013.

43. Dolovich MA, MacIntyre NR, Anderson PJ, Camargo CA Jr, Chew $\mathrm{N}$, Cole $\mathrm{CH}$, et al. Consensus statement: aerosols and delivery devices. American Association for Respir Care. Respir Care 2000; 45(6):589-596.

44. Duarte AG. Inhaled bronchodilator administration during mechanical ventilation. Respir Care 2004;49(6):623-634.

45. Hasegawa EA. The endotracheal use of emergency drugs. Heart Lung 1986;15(1):60-63.

46. Neumar RW, Otto CW, Link MS, Kronick SL, Shuster M, Callaway CW, et al. Part 8: adult advanced cardiovascular life support: 2010 American Heart Association Guidelines for Cardiopulmonary Resuscitation and Emergency Cardiovascular Care. Circulation 2010; 122(18 Suppl 3):S729-S767.

47. Pillow JJ, and Minocchieri S. Innovation in surfactant therapy II: surfactant administration by aerosolization. Neonatology 2012; 101(4):337-344.

48. Polin RA, and Carlo WA. Surfactant replacement therapy for preterm and term neonates with respiratory distress. Pediatrics 2014; 133(1):156-163.

49. MacIntyre NR. Intratracheal catheters as drug delivery systems. Respir Care 2001;46(2):193-197.

50. Gillis HL, and Lutchen KR. How heterogeneous bronchoconstriction affects ventilation distribution in human lungs: a morphometric model. Ann Biomed Eng 1999;27(1):14-22.

51. Byron PR, Hindle M, Lange CF, Longest PW, McRobbie D, Oldham $\mathrm{MJ}$, et al. In vivo-in vitro correlations: predicting pulmonary drug deposition from pharmaceutical aerosols. J Aerosol Med Pulm Drug Deliv 2010;23(Suppl 2):S59-S69.

52. AARC clinical practice guideline: selection of device, administration of bronchodilator, and evaluation of response to therapy in mechanically ventilated patients. Respir Care 1999;44(1):105-113.

53. MacIntyre NR. Aerosol delivery through an artificial airway. Respir Care 2002;47(11):1279-1288; discussion 1285-1289.

54. Duarte AG, Momii K, and Bidani A. Bronchodilator therapy with metered-dose inhaler and spacer versus nebulizer in mechanically ventilated patients: comparison of magnitude and duration of response. Respir Care 2000;45(7):817-823.

55. Hendeles L, Hatton RC, Coons TJ, Carlson L. Automatic replacement of albuterol nebulizer therapy by metered-dose inhaler and valved holding chamber. Am J Health Syst Pharm 2005;62(10):1053-1061.

This article is approved for Continuing Respiratory Care Education credit. For information and to obtain your CRCE

(free to AARC members) visit

www.rcjournal.com

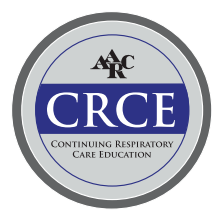

